I set up, with unanimous support from colleagues, the N. Ireland Section of the Irish Division. The NHS provisions and changes which we had been able to monitor and follow when there was the Irish Division of the RMPA necessitated a continuity of linkup through the Irish Division of the new Royal College. It seems this Irish solution to an Irish problem has worked, our colleagues in the south realising that, although NHS involvement is only in a small area of the total island, the population of N. Ireland is just about half of that of the Republic.

Ivor has stuck to his vision of community psychiatry development over the years. I have nothing but admiration for this, seeing it from a close viewpoint without personal involvement, when others have held equally sincerely opposing views. Ireland has produced several distinguished psychiatrists but it is pleasant to see one who has given such admirable service at home honoured by a special place in the Bulletin.

Purdysburn Hospital

W. A. Gordon MacCallum Belfast BT8 8BH

\section{Mental handicap training}

DEAR SIRS

Reading 'Training Psychiatrists for Work in the Community' (Psychiatric Bulletin, 16, 23-24) there is evident similarity between the issues now being looked at in community psychiatry and those looked at in community mental handicap services at the beginning of the ' 80 s. Perhaps this reflects the current position of mental handicap on the spectrum between biological and social disorders, it being considered more of a social problem than general psychiatry despite its more obvious organic roots.

Trainers in general psychiatry might look at mental handicap training to see how issues of the hospital v. community, multidisciplinary team working, and clinical role $v$. organiser, have been worked out within the community mental handicap services. Many senior registrars in mental handicap spend time within a hospital service and time within community services as part of community mental handicap teams, and through this community service gain experience within the full range of community settings.

Community settings are less structured than hospital settings and it is easy to get sucked into managerial and organisational meetings and while these have their value, trainees must learn how to protect clinical time; it is knowledge of patients which informs these other roles of the consultant. Most problematic has been the relationship between the consultant and other team members, and no doubt this is one of the major issues within community psychiatric services. There is much written on this topic and many models have emerged. The understanding of other disciplines is an essential part of training as this allows the consultant to take some over-view and not become bogged down in interdisciplinary dispute.

If general psychiatry trainers are wondering how to give trainees organised and supervised experience in community psychiatric settings, it may be worth looking at the local mental handicap services for part-time sessional input which might be of mutual benefit to both services and training.

\section{Paddington Community Hospital}

J. Piachaud

$7 a$ Woodfield Road

London W9 $2 B B$

\section{Psychiatric training in Singapore}

\section{DeAR SIRS}

Robertson et al's article on psychiatric training in Singapore (Psychiatric Bulletin, January 1992, 16, 36-38) stated that "suicide remains an offence under Singaporean law, but no action is taken for deliberate self-harm, unless it is related to national service". This implies that some form of disciplinary action will be taken in cases of deliberate self-harm related to national service, which is not entirely accurate.

Based on my experience as a psychiatrist in the armed forces, all cases of deliberate self-harm are reported. A board of inquiry will be convened and its findings submitted to a review board. The review board sits to discuss the findings and these reports are routinely circulated to the psychiatrist for an opinion on the soldier's mental competency (Lim \& Ang, 1992). Depending on the causes, appropriate action will then be taken. Disciplinary action is not the only means of disposal. Very frequently, the soldier concerned is referred for counselling, or to a psychiatrist for treatment of an underlying psychiatric problem.

Department of Psychological Medicine LIONEL CHEE-CHONG LIM

National University of Singapore

(Currently: Research Psychiatrist, Institute of Psychiatry, De Crespigny Park, London SE5 8AF).

\section{Reference}

LiM, L. C. C. \& ANG, Y. G. (1992) Parasuicide in the male conscripts - a Singapore experience. Military Medicine (in press).

\section{Senior registrar in psychotherapy}

\section{DeAr Sirs}

Competition for public sector funds will set medical psychotherapists against others, especially clincal psychologists. Other disciplines will compete very favourably, on price. They will also often compete 